\title{
Selective graft-versus-leukemia depends on magnitude and diversity of the alloreactive $\mathrm{T}$ cell response
}

\author{
Cornelis A.M. van Bergen, ${ }^{1}$ Simone A.P. van Luxemburg-Heijs, ${ }^{1}$ Liesbeth C. de Wreede, ${ }^{2}$ Matthijs Eefting, ${ }^{1}$ Peter A. von dem Borne, \\ Peter van Balen, ${ }^{1}$ Mirjam H.M. Heemskerk, ${ }^{1}$ Arend Mulder, ${ }^{3}$ Fransiscus H.J. Claas, ${ }^{3}$ Marcelo A. Navarrete, ${ }^{4}$ Wilhelmina M. Honders, \\ Caroline E. Rutten, ${ }^{1}$ Hendrik Veelken, ${ }^{1}$ Inge Jedema, ${ }^{1}$ Constantijn J.M. Halkes, ${ }^{1}$ Marieke Griffioen, ${ }^{1}$ and J.H. Frederik Falkenburg ${ }^{1}$ \\ DDepartment of Hematology, ${ }^{2}$ Department of Medical Statistics and Bioinformatics, and ${ }^{3}$ Department of Immunohematology and Blood Transfusion, Leiden University Medical Center, Leiden, Netherlands. \\ ${ }^{4}$ School of Medicine, University of Magallanes, Punta Arenas, Chile.

\begin{abstract}
Patients with leukemia who receive a T cell-depleted allogeneic stem cell graft followed by postponed donor lymphocyte infusion (DLI) can experience graft-versus-leukemia (GVL) reactivity, with a lower risk of graft-versus-host disease (CVHD). Here, we have investigated the magnitude, diversity, and specificity of alloreactive CD8 T cells in patients who developed GVL reactivity after DLI in the absence or presence of CVHD. We observed a lower magnitude and diversity of CD8 T cells for minor histocompatibility antigens (MiHAs) in patients with selective GVL reactivity without GVHD. Furthermore, we demonstrated that MiHA-specific T cell clones from patients with selective CVL reactivity showed lower reactivity against nonhematopoietic cells, even when pretreated with inflammatory cytokines. Expression analysis of MiHA-encoding genes showed that similar types of antigens were recognized in both patient groups, but in patients who developed CVHD, T cell reactivity was skewed to target broadly expressed MiHAs. As an inflammatory environment can render nonhematopoietic cells susceptible to $\mathrm{T}$ cell recognition, prevention of such circumstances favors induction of selective GVL reactivity without development of CVHD.
\end{abstract}

\section{Introduction}

The curative effect of allogeneic stem cell transplantation (alloSCT) as a treatment modality for hematological malignancies is based on the capacity of donor $\mathrm{T}$ cells to effectively induce graft-versus-leukemia (GVL) reactivity against malignant hematopoietic cells from the patient (1-3). Alloreactive donor-derived $\mathrm{T}$ cells may, however, also target normal nonhematopoietic tissue cells, resulting in potentially life-threatening graft-versus-host disease (GVHD) (4). T cell depletion of the graft can prevent GVHD but also impairs development of the associated GVL effect $(5,6)$. Persistent or recurring malignant hematopoietic cells after alloSCT will then require elimination by subsequent donor lymphocyte infusion (DLI) (7-12). The observation that $\mathrm{T}$ cell depletion followed by postponed DLI reduces the development of GVHD after alloSCT can be explained by the timing of DLI, when prealloSCT chemotherapy-induced tissue damage and infections have largely been resolved, the "cytokine storm" has subsided, and patient-derived antigen-presenting cells (APC) that can induce an immune response are gradually being replaced by donor APCs $(3,12,13)$. Although $\mathrm{T}$ cell depletion of the graft followed by DLI reduces the incidence and severity of GVHD, this complication remains a serious risk factor for morbidity and mortality $(14,15)$.

Alloreactive $\mathrm{T}$ cells recognize non-self antigens on patient cells encoded by patient-specific genomic polymorphisms. In fully HLA-matched alloSCT, target antigens are minor histocompatibility antigens (MiHAs), which are polymorphic peptides presented in

Conflict of interest: The authors have declared that no conflict of interest exists Submitted: February 9, 2016; Accepted: November 17, 2016.

Reference information: J Clin Invest. 2017;127(2):517-529.

https://doi.org/10.1172/JCl86175
self-HLA encoded by SNPs $(16,17)$. Genomic disparities between donor and patient therefore determine the potential antigen repertoire that can be targeted by donor T cells. The tissue distribution of HLA class I-restricted MiHAs is a relevant factor that determines the clinical effect of donor CD8 T cells after alloSCT. Donor T cells recognizing MiHAs with restricted expression on hematopoietic cells, including the malignant cells of the patient, are expected to induce selective GVL reactivity. Donor CD8 T cells recognizing MiHAs with ubiquitous expression on both hematopoietic and nonhematopoietic tissues are more likely to mediate both GVL reactivity and GVHD (18). In the fully HLA-matched setting, CD4 T cells are less likely to contribute to GVHD due to restricted expression of HLA class II. Clinical studies of infusion of purified CD4 T cells indeed showed a reduced risk for GVHD (19-21).

In the past decade, increasing numbers of MiHAs have been characterized mainly due to the application of whole-genome association scanning (WGAs) (22). We identified multiple MiHAs by WGAs and demonstrated in several patients that at least 3 to 8 different HLA class I-restricted MiHAs were targeted by donor CD8 T cells after HLA-matched alloSCT and DLI (23-25). While severe GVHD frequently coincides with the development of $\mathrm{T}$ cell responses against ubiquitously expressed MiHAs, relatively selective GVL reactivity was not always associated with $\mathrm{T}$ cell responses recognizing MiHAs selectively expressed by hematopoietic cells $(23,24,26)$. Apparently, other factors also determine the balance between GVL reactivity and GVHD. We hypothesized that, in addition to tissue specificity, the magnitude and diversity of the immune response will influence this balance. Moreover, the effects of immune responses are subject to environmental factors, such as the presence of inflammatory cytokines and chemokines, which are influenced by infections, tissue 
damage, and exogenous immune-regulatory drugs. Inflammatory cytokines may upregulate the surface expression of HLA and costimulatory and adhesion molecules and modify antigen processing and presentation, resulting in differential clinical effects of donor T cells capable of recognizing MiHAs on various tissues from the patient (27).

In this study, we characterized alloreactive CD8 T cell responses in 11 patients who entered complete remission and/or full donor chimerism after DLI. We investigated the magnitude of the response, defined as the abundance of alloreactive $\mathrm{T}$ cell clones within the activated CD8 T cell compartment; diversity, defined as the number of different MiHAs that were targeted and the number of MiHA-specific $\mathrm{T}$ cell clones with different TCR- $\beta$ chains; and tissue specificity, defined as the capacity of alloreactive $\mathrm{T}$ cell clones to recognize MiHAs on hematopoietic and nonhematopoietic cells. Our data show that the frequency as well as diversity of MiHA-specific CD8 T cells were lower in patients with selective GVL reactivity as compared with patients with GVHD. In patients with selective GVL reactivity, immune responses were skewed toward T cells that failed to recognize patient nonhematopoietic fibroblasts (FBs). We identified 19 MiHAs, including 13 novel and 6 known MiHAs, and illustrate that tissue distribution of MiHA-encoding genes is not the main determinant that separates GVL reactivity from GVHD, but that inflammatory environmental circumstances also contribute to overcome the threshold for GVHD development.

\section{Results}

Patient selection. To compare CD8 T cell responses in GVL reactivity and GVHD after DLI, we selected 11 patients who were treated for chronic myeloid leukemia in the chronic phase (CML-CP), acute myeloid leukemia (AML), or high-risk myelodysplastic syndrome (MDS) between 2000 and 2010 with a T cell-depleted stem cell graft from a fully HLA-matched sibling or unrelated donor. Pretransplant conditioning was either myeloablative (cyclophosphamide and total body irradiation) or nonmyeloablative (fludarabin, busulphan, and in vivo $\mathrm{T}$ cell depletion using alemtuzumab combined with horse antithymocyte globulin [ATG] if the donor was unrelated). Peripheral blood stem cells were the main stem cell source. After engraftment and development of no or limited grade I GVHD, patients with mixed chimerism or residual or relapsed disease were treated with escalating doses of donor lymphocytes, starting at 6 months with $3 \times$ $10^{6} \mathrm{CD} 3 \mathrm{~T}$ cells/kg until a response was observed. Patients with unre-
A

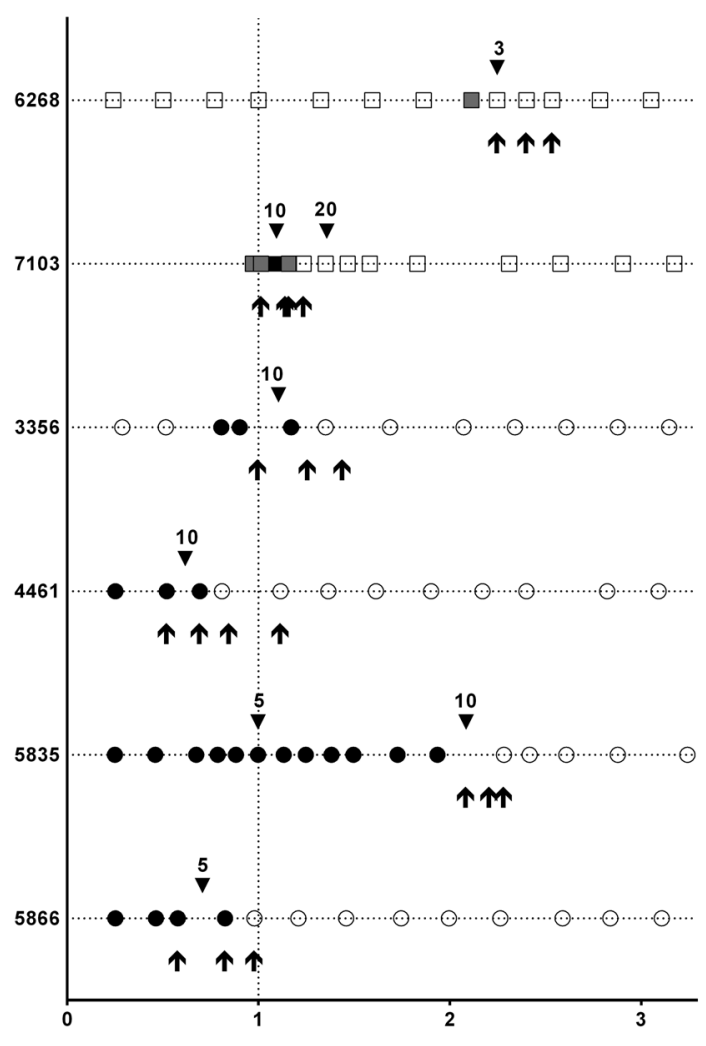

B

GVL + GVHD

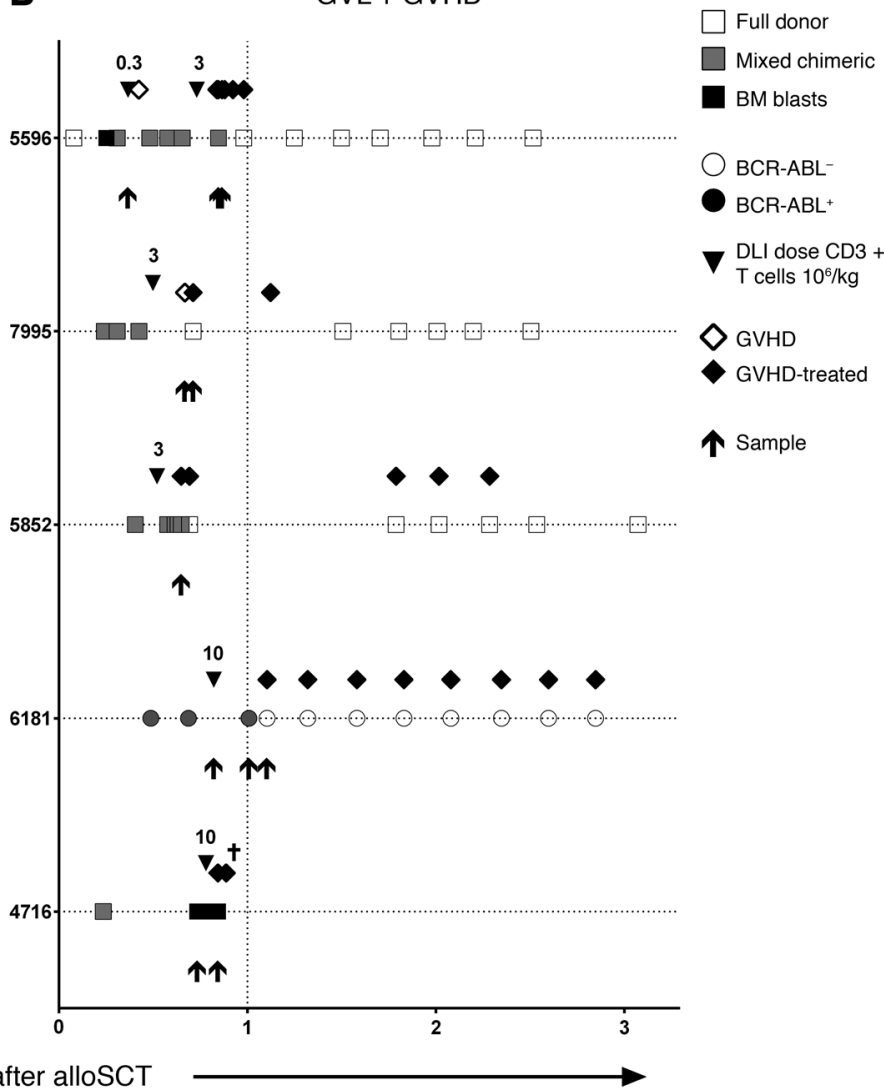

Figure 1. Clinical course of selected patients. Interventions and follow-up for each patient are depicted on the horizontal dotted lines. Regular monitoring after alloSCT was conducted to detect donor chimerism (squares) or BCR-ABL (circles) by PCR and the presence of blasts in bone marrow aspirates as determined by morphology. White symbols indicate full donor chimerism or absence of disease. Disease recurrence was detected by the presence of blasts by bone marrow morphology (black squares), detectable $B C R-A B L$ transcripts (black circles), or mixed chimerism (gray squares). DLI was administered (black triangles; doses were given in $10^{6}$ CD3 T cells $/ \mathrm{kg}$ ), and patients experienced selective GVL reactivity $(n=6, \mathbf{A})$ or were diagnosed with GVHD ( $n=5$, white diamonds, B), requiring systemic immunosuppressive treatment (black diamonds). Arrows indicate collected samples. Vertical dotted line indicates 1 year after DLI. Patient 4716 died 74 days after DLI. For detailed patient characteristics, see Supplemental Table 1. 


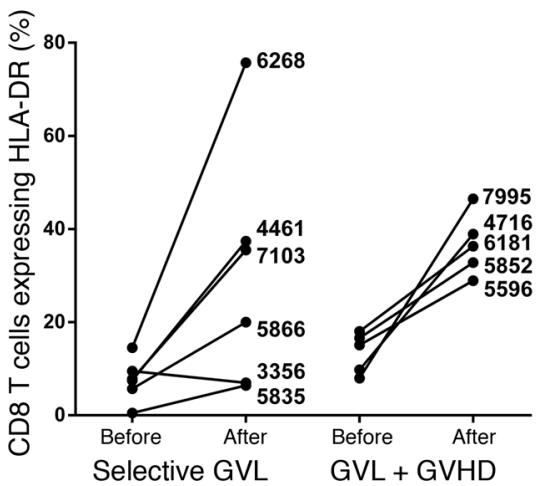

Figure 2. HLA-DR expression on CD8 T cells. In samples taken before and after DLI, HLA-DR+ ${ }^{+}$CD8 T cells were detected by flow cytometry. Percentages of CD8 T cells that expressed HLA-DR are depicted. Lines connect pre- and post-DLI samples for each patient (patient IDs are indicated in the graph).

lated donors received $1.5 \times 10^{6} \mathrm{CD} 3 \mathrm{~T}$ cells $/ \mathrm{kg}$ as a starting dose. We selected 11 patients on the basis of well-documented GVL reactivity and an absence or presence of GVHD and availability of samples at relevant time points before and after DLI. With the exception of patient 7103, no cytoreductive treatment was administered prior to DLI (Supplemental Table 1; supplemental material available online with this article; doi:10.1172/JCI86175DS1). Post-DLI samples were taken at routine follow-up time points and upon development of GVHD. GVL reactivity was defined by a conversion to full donor chimerism or a disappearance of leukemic cells, indicating molecular remission. Of the 11 patients, 6 remained free of GVHD (Figure 1A), while 5 patients developed GVHD and received systemic immunosuppressive treatment (Figure 1B and Supplemental Table 1). Four of six patients without GVHD were treated with DLI in the second year after alloSCT, whereas all five patients with GVHD received DLI in the first year after alloSCT. Of the 11 patients, 1 died 74 days after DLI as a result of complications related to grade IV GVHD and therefore could not be evaluated for long-term GVL reactivity. In the other 10 patients, curative GVL reactivity was established, and all patients were alive between 5 and 15 years after alloSCT.

Selection of alloreactive $T$ cells. We first analyzed the overall immune response after DLI by deep sequencing of the TCR- $\beta$ transcriptome of purified CD8 $\mathrm{T}$ cells. Within the repertoire of TCR- $\beta$ sequences, a clonotype is defined as a unique T cell receptor- $\beta$ (TCR- $\beta$ ) sequence. The abundance of a clonotype within the total number of identified TCR- $\beta$ transcripts was correlated with the frequency of T cells expressing that TCR- $\beta$ (see also Supplemental Table 2: T cell receptor- $\beta$ sequencing analysis). Simpson's diversity indices were comparable between pre- and post-DLI samples, except for patient 7995, for whom the pre-DLI sample was dominated (93\%) by a single clone. After DLI, however, this clone decreased to $21 \%$, resulting in an increased diversity index. We did not observe a unidirectional change of TCR- $\beta$ diversity between pre- and post-DLI samples. Since diversity indices were similar between patients with GVHD and those without GVHD, we conclude that post-DLI $\mathrm{T}$ cell repertoires are not dominated by responding alloreactive T cells. All unique TCR- $\beta$ clonotypes with frequencies of greater than $0.1 \%$ after DLI were selected and considered "expanding" if their frequencies increased by at least 100-fold compared with pre-DLI frequencies. The data showed that the median number of expanding clonotypes was lower in patients without GVHD (24, range 9-87) than in those with GVHD (58, range 47-116), but this difference did not reach statistical significance $(P=0.095)$. Expanding TCR- $\beta$ clonotypes may include alloreactive $\mathrm{T}$ cell responses but are likely to be dominated by pathogen-specific $\mathrm{T}$ cell responses. Since we hypothesized that recently activated CD8 $\mathrm{T}$ cells in post-DLI immune responses expressed HLA-DR, we analyzed the frequencies of circulating HLA-DR ${ }^{+}$CD8 T cells in samples before and after DLI by flow cytometry (Figure 2 ). The percentage of HLA-DR ${ }^{+} \mathrm{CD} 8 \mathrm{~T}$ cells increased significantly from $10.3 \% \pm 5.3 \%$ (mean \pm SD) in pre-DLI samples to $33.2 \% \pm 19.1 \%$ in post-DLI samples, irrespective of GVHD status $(P=0.002)$. To identify the compartment in which the alloreactive $\mathrm{T}$ cells resided, HLA-DR ${ }^{+}$and HLA-DR ${ }^{-} \mathrm{T}$ cells were separately isolated from post-DLI samples of patients 4461, 5866, and 6181. T cell clones were generated from sorted single cells and tested for alloreactivity, as defined by recognition of the patient EBV-transformed B lymphoblastic cell line (EBVLCL) exceeding at least 5 times the background release of IFN- $\gamma$ by the $\mathrm{T}$ cell clone and a complete absence of recognition of the donor EBV-LCL. Of $261 \mathrm{~T}$ cell clones obtained from sorted HLA$\mathrm{DR}^{+} \mathrm{CD} 8 \mathrm{~T}$ cells, $41 \mathrm{~T}$ cell clones were alloreactive, whereas only 1 alloreactive $\mathrm{T}$ cell clone was identified in $268 \mathrm{~T}$ cell clones from HLA-DR ${ }^{-}$cells. In contrast, the numbers of EBV-LCL-reactive T cell clones, as defined by recognition of both patient and donor EBV-LCLs, were similar in HLA-DR ${ }^{+}$and HLA-DR ${ }^{-}$compartments (data not shown). Tetramer staining of EBV-LCL-reactive T cell clones from patient 5866 revealed that $56 \%$ of the $\mathrm{T}$ cell clones recognized validated $\mathrm{EBV}$ epitopes derived from the viral proteins BRLF1, BMFL1, EBNA3B, or BZLF1 (data not shown). Whereas pathogen-specific $\mathrm{T}$ cells were present in both the HLA-DR ${ }^{+}$and HLA-DR ${ }^{-}$compartments, our results confirmed that alloreactive $\mathrm{T}$ cells during clinical immune responses after DLI specifically reside in the HLA-DR ${ }^{+} \mathrm{CD} 8 \mathrm{~T}$ cell compartment.

Frequencies of alloreactive $T$ cells. To compare the magnitude of alloreactive T cell responses in GVL and GVHD, we selected 20 samples from 6 patients who developed selective GVL reactivity without GVHD and 12 samples from 5 patients with GVHD. HLA-DR ${ }^{+}$CD8 T cells were single-cell sorted, and $\mathrm{T}$ cell clones were tested for reactivity against patient and donor EBV-LCLs. In addition, if sufficient pre-alloSCT cells were available, we tested $\mathrm{T}$ cell reactivity against monocyte-derived DCs (monoDCs) and B cells that were expanded using CD40L-expressing mouse fibroblasts (CD40L B cells) (Supplemental Table 3). Alloreactive T cell clones were defined by recognition of the patient cells exceeding at least 5 times the background release of IFN- $\gamma$ and a complete absence of recognition of the donor cells. For each sample, we determined the contribution of alloreactive $\mathrm{T}$ cell clones (Figure $3 \mathrm{~A}$ ). The median percentage of alloreactive $\mathrm{T}$ cell clones in post-DLI samples was significantly lower in patients without GVHD (0.6\%, range 0\%-17.1\%) than in those with GVHD (30\%, range $0.5 \%-36.6 \%, P=0.001$ ). In addition to alloreactive $\mathrm{T}$ cells, we isolated $\mathrm{T}$ cell clones that recognized both patient and donor EBV-LCLs. These T cell clones did not react with monoDCs and CD4OL-activated B cells, illustrating a recognition of antigens expressed by B cells after EBV transformation. In 4 of 6 patients 


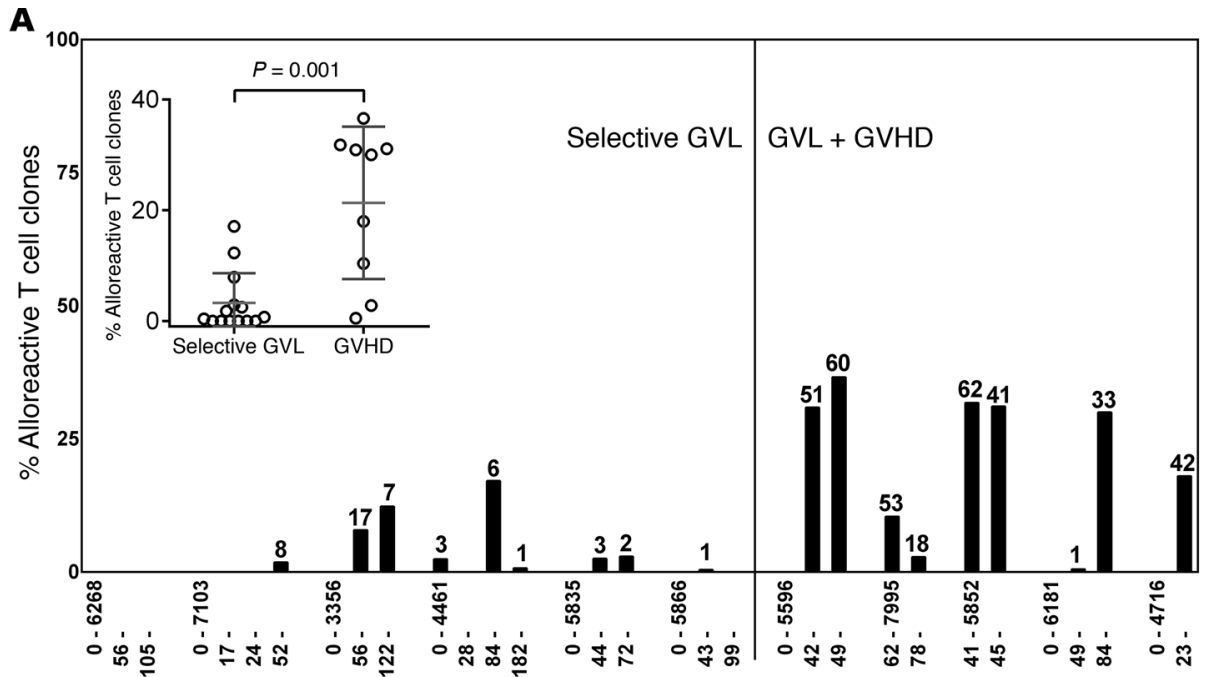

Days after DLI — patient ID

B

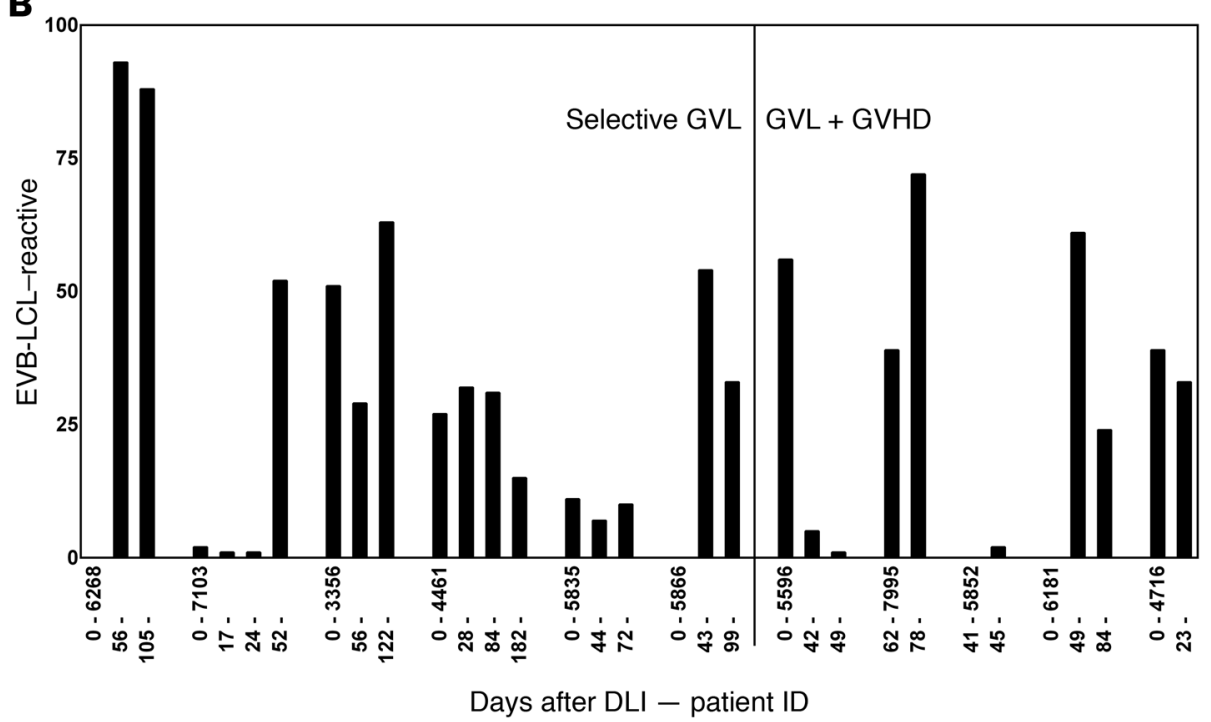

Figure 3. Frequencies of alloreactive $T$ cells. $\mathrm{HLA}-\mathrm{DR}{ }^{+} \mathrm{CD} 8 \mathrm{~T}$ cells were single-cell sorted and expanded from samples taken before (day 0 ) and after DLI. Patients were stratified by development of GVHD, and time points of sample collection are indicated for each patient on the $x$ axis. The percentages of tested $T$ cell clones that were alloreactive (A) or EBV-LCL reactive (B) are shown on the $y$ axis. (A) Alloreactive $T$ cell clones were defined by recognition of patient EBV-LCLs exceeding at least 5 times the background release of IFN- $\gamma$ by the $\mathrm{T}$ cell clone alone and a complete absence of recognition of donor EBV-LCLs. Absolute numbers of identified alloreactive $T$ cell clones are depicted on top of the bars. The percentages of alloreactive T cell clones in post-DLI samples were compared between patients with selective GVL reactivity and patients with GVHD using an unpaired Mann-Whitney $U$ test (insert). (B) In the same samples, T cell clones recognizing EBV-LCLs from both the patient and donor were quantified and depicted as a percentage of the total number of isolated T cell clones. No differences in the percentages of EBV-LCL-reactive $T$ cell clones were detected between patients with selective GVL reactivity and those with GVHD. See Supplemental Table 3 for sorting details and tested stimulator cells. without GVHD and 3 of 5 patients with GVHD, more than $50 \%$ of the $\mathrm{T}$ cell clones were EBV-LCL reactive, illustrating that patients in both groups were equally capable of eliciting antiviral immune responses and that the low frequencies of alloreactive $\mathrm{T}$ cells in patients without GVHD cannot be explained by a general suppression of the immune system (Figure 3B). To exclude the possibility that alloreactive $\mathrm{T}$ cells that lack reactivity against hematopoietic cells were missed during screening, all growing T cell clones from 3 patients with GVHD were tested against patient FBs (Supplemental Table 3). To obtain maximal sensitivity, FBs were preactivated for 4 days with IFN- $\gamma(200 \mathrm{IU} / \mathrm{ml})$. No T cell clones that recognized FBs in the absence of recognition of EBV-LCL were identified (data not shown). In conclusion, our data show that patients with GVHD after DLI have higher frequencies of circulating alloreactive CD8 T cells than do patients without GVHD.

Diversity of alloreactive $T$ cells. To investigate the functional diversity of the alloreactive $\mathrm{T}$ cell clones, we determined HLA restriction, MiHA frequencies, and TCR- $\beta$ clonality for 31 clones from patients with selective GVL reactivity and 127 clones from patients with GVHD. HLA restriction was determined using broad and allele-specific HLA-blocking antibodies and by retroviral transduction of third-party EBV-LCLs with the relevant HLA class I restriction allele (Table 1 and Supplemental Table 4). To determine whether the $\mathrm{T}$ cell clones were specific for the same MiHA, we tested the recognition of 24 EBV-LCLs that endogenously expressed HLA- $\mathrm{A}^{*} 02$ and $\mathrm{B}^{\star} 07$ (data not shown). This panel was retrovirally transduced with the relevant HLA class I restriction allele for $\mathrm{T}$ cell clones recognizing MiHAs restricted to other HLA molecules. The data showed recognition of 67 different MiHAs. Of these antigens, 19 MiHAs were targeted in patients without GVHD, and 48 MiHAs were targeted in patients with GVHD (Table 1). The median number of MiHAs recognized in patients with selective GVL reactivity was 3.0 (range 1-10) as compared with 11.0 (range $4-18, P=0.056$ ) in patients with GVHD. Since different $\mathrm{T}$ cells can target the same MiHA, we also investigated $\mathrm{T}$ cell diversity on the basis of the number of TCR- $\beta$ transcripts and identified 79 unique TCR- $\beta$ clonotypes. TCR- $\beta$ diversity was again lower in patients with selective GVL reactivity (median 4.0, range 1-10) than in patients with GVHD (median 13, range 5-22, $P=0.040)$. In addition, for each patient, we estimated the pro- 
Table 1. Response diversity

\begin{tabular}{|c|c|c|c|c|c|c|c|c|c|c|}
\hline \multirow[t]{2}{*}{ Patient ID } & \multicolumn{5}{|c|}{ MiHA diversity ${ }^{A}$} & \multirow[t]{2}{*}{$\begin{array}{l}\text { CDR3 diversity of } \\
\text { alloreactive TCR- } \beta^{B}\end{array}$} & \multicolumn{2}{|c|}{ Simpson's diversity index } & \multicolumn{2}{|c|}{$\begin{array}{c}\text { Contribution of alloreactive TCR- } \beta \\
\text { within total CD8 TCR- } \beta \text { repertoire }(\%)^{c}\end{array}$} \\
\hline & HLA-A & HLA-B & HLA-C & Unknown & Total & & Before DLI & After DLI & before DLI & after DLI \\
\hline 7103 & 1 & & & & 1 & 2 & 0.85 & 0.75 & 0.00 & 4.14 \\
\hline 3356 & 3 & 7 & & & 10 & 10 & 0.92 & 0.93 & 0.00 & 0.76 \\
\hline 4461 & 2 & 2 & & & 4 & 4 & 0.82 & 0.89 & 0.00 & 0.66 \\
\hline 5835 & & 1 & 2 & & 3 & 5 & 0.94 & 0.96 & 0.00 & 0.09 \\
\hline 5866 & & 1 & & & 1 & 1 & 0.84 & 0.94 & 0.00 & 9.27 \\
\hline 5596 & 7 & 4 & & & 11 & 13 & 0.79 & 0.98 & 0.02 & 7.91 \\
\hline 7995 & 1 & 2 & 1 & & 4 & 6 & 0.14 & 0.89 & 0.00 & 6.95 \\
\hline 5852 & 6 & 8 & 3 & 1 & 18 & 22 & 0.88 & 0.95 & 0.71 & 10.38 \\
\hline 6181 & 1 & 3 & & & 4 & 5 & 0.78 & 0.72 & 0.17 & 57.62 \\
\hline 4716 & 4 & 6 & & 1 & 11 & 16 & 0.92 & 0.98 & 1.10 & 3.01 \\
\hline
\end{tabular}

${ }^{A}$ Numbers represent the number of different MiHAs recognized by isolated T cell clones as determined by antibody blocking and panel studies. ${ }^{B} \mathrm{CDR} 3$

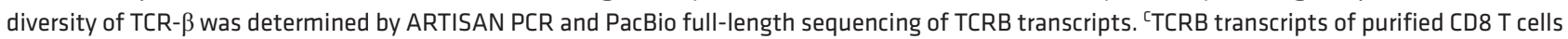
were amplified by ARTISAN PCR and sequenced using an Illumina HiSeq 2500 system. CDR3 nucleotide sequences of MiHA-specific T cell clones were quantified within the repertoire of TCR- $\beta$. For detailed data on the T cell clones, see Supplemental Table 4. For detailed data on TCR- $\beta$ deep sequencing, see Supplemental Table 2: T cell receptor- $\beta$ sequencing analysis.

portion of the identified TCR- $\beta$ clonotypes within the entire TCR- $\beta$ repertoire of purified CD8 T cells from samples before and after DLI. The median contribution of alloreactive CD8 T cells in post-DLI samples from patients with selective GVL reactivity was $0.76 \%$ (range $0.09 \%-9.27 \%$ ) as compared with $7.91 \%$ (range 3.01\%-57.62\%) in patients with GVHD ( $P=0.095$, Table 1 and Supplemental Table 4). In conclusion, our data show that the repertoire of targeted MiHAs and the diversity of responding alloreactive $\mathrm{T}$ cells are more restricted in patients with selective GVL reactivity than in those with GVHD.

Tissue specificity of alloreactive $T$ cells. We next investigated whether MiHAs targeted in patients with selective GVL reactivity were expressed on different cell types compared with MiHAs targeted in patients with GVHD. T cell clones were tested against titrated numbers of hematopoietic cells (EBV-LCLs, Figure 4A) and compared between patients with GVHD and those with selective GVL reactivity. As nonhematopoietic cells, FBs obtained from skin biopsies were tested. FBs were cultured in the absence of cytokines (steady-state FBs, Figure 4B) or in the presence of IFN- $\gamma$ (200 $\mathrm{IU} / \mathrm{ml}$ ) for 4 days to mimic inflammatory conditions (IFN- $\gamma$-treated FBs, Figure 4C). Under inflammatory conditions sensitivity for $\mathrm{T}$ cell recognition can increase as a result of higher expression of HLA and proteins involved in antigen processing, costimulation, and adhesion $(4,13)$. We quantified $\mathrm{T}$ cell recognition by calculating the absolute amount of IFN- $\gamma$ produced per single $\mathrm{T}$ cell during overnight stimulation. Recognition of FBs was absent or low as compared with recognition of EBV-LCLs by most $\mathrm{T}$ cell clones. Comparison of stimulation including the entire range of stimulator/T cell ratios was performed by mixed-models statistical analysis (see also "Mixed models statistical analysis" in the Supplemental Experimental Procedures). The data showed that, upon stimulation with patient EBV-LCLs, IFN- $\gamma$ production by alloreactive T cell clones was comparable between patients with GVHD (137.0 fg IFN$\gamma / \mathrm{T}$ cell/20 h) and patients with selective GVL reactivity ( $87.8 \mathrm{fg}$ IFN- $\gamma / \mathrm{T}$ cell $/ 20 \mathrm{~h}, P=0.26$ at a ratio of 9:1) (Figure $4 \mathrm{D}$ ). Stimulation by steady-state $\mathrm{FB}$ revealed a trend toward higher IFN- $\gamma$ production by $\mathrm{T}$ cell clones from patients with GVHD ( $1.9 \mathrm{fg}$ IFN- $\gamma / \mathrm{T}$ cell $/ 20 \mathrm{~h}$ ) as compared with patients with selective GVL reactivity ( $0.7 \mathrm{fg}$ IFN$\gamma / \mathrm{T}$ cell $/ 20 \mathrm{~h}, P=0.10$ at a ratio of $1: 1$ ) (Figure $4 \mathrm{E}$ ). This difference reached statistical significance when $\mathrm{T}$ cell clones were stimulated with IFN- $\gamma$-treated FBs (GVHD: 4.4 fg IFN- $\gamma / \mathrm{T}$ cell/20 h; selective GVL reactivity: 1.3 fg IFN- $\gamma / \mathrm{T}$ cell/20 h, $P=0.03$ ) (Figure $4 \mathrm{~F}$ ). We observed similar results when FBs were incubated with IFN- $\gamma$ in combination with TNF- $\alpha(10 \mathrm{ng} / \mathrm{ml})$ and IL-4 (500 IU/ml) (see also "Mixed models statistical analysis" in the Supplemental Experimental Procedures). In conclusion, $\mathrm{T}$ cell clones recognizing MiHAs that are presented on both hematopoietic EBV-LCLs and nonhematopoietic FBs were more frequently found in patients with GVHD.

Antigen specificity. To molecularly characterize the MiHAs that were targeted by the isolated $\mathrm{T}$ cell clones, we applied WGAs to detect MiHA-encoding SNPs. T cell clones restricted to HLA-A ${ }^{*} 2$ or $\mathrm{B}^{*} \mathrm{O} 7$ were tested on an extensive panel of SNP-genotyped EBV-LCLs that endogenously expressed these HLA molecules (24). T cell clones restricted to other HLA class I molecules were tested against the same EBV-LCL panel after retroviral transduction of the relevant HLA molecule. We analyzed $\mathrm{T}$ cell clones for 19 MiHAs targeted in patients with selective GVL reactivity and 48 MiHAs targeted in patients with GVHD. Three T cell clones selectively recognized male EBV-LCLs, indicating recognition of $\mathrm{Y}$ chromosome-encoded antigens, which was confirmed in one case by staining with $K D M 5 D-A^{*} 02$ tetramers (Table 2). For the remaining specificities, we identified 23 associating SNPs. T cell clones from patients 5569 and 4716 were associated with an identical SNP in the NDC80 gene. For the 22 unique associations, 13 SNPs were located in coding sequences of known genes, and 9 SNPs were located in noncoding regions. For the latter 9 SNPs, sequencing revealed additional donor-to-patient SNP disparities in 6 cases, 5 of which were located in coding exons and 1 in a genomic region that was not known to contain a functional gene but encoded an amino acid polymorphism in a 255-bp ORF. For 
A

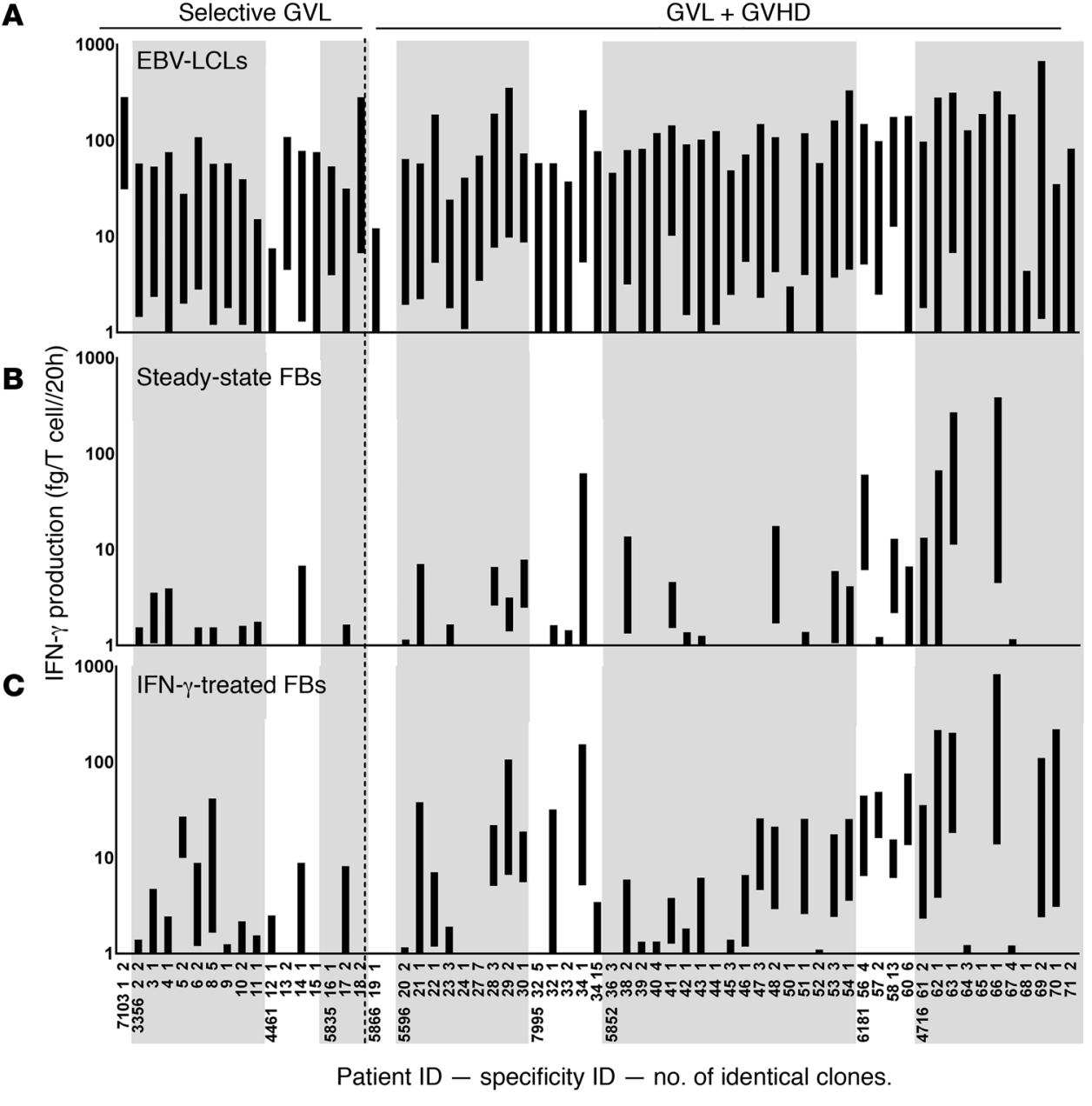

Figure 4. Tissue specificity of alloreactive $\mathbf{T}$ cell clones. $(\mathbf{A}-\mathbf{C}) \mathrm{T}$ cell clones representing the specificities targeted in patients with selective GVL reactivity (18 $\mathrm{T}$ cell clones, left) and patients with GVHD (46 T cell clones, right) were incubated at 833 and 2,500 T cells per well with 0.1-, 0.3-, 1-, 3-, and 9-fold excess of stimulator cells. On the $x$ axis, $T$ cell specificities are plotted for each patient, including the number of isolated $T$ cell clones with identical specificity (see also "Response diversity " in Supplemental Table 4). The following cells were used for stimulation: EBV-LCLs (A), FBs cultured under steady-state conditions (B), and FBs cultured for 4 days with $200 \mathrm{IU} / \mathrm{ml} \mathrm{IFN}-\gamma$ (C). Bars represent the dose-response range between the lowest and highest ratio of stimulator cells as measured by the production of IFN- $\gamma$ in femtograms per single $T$ cell per 20 hours. (D-F) Mixed-models statistical analysis was applied to compare doseresponse ranges between $T$ cell clones from patients with selective GVL reactivity (dashed line) and those with GVHD (solid line) after stimulation with EBV-LCLs (D), steady-state FBs (E), and IFN- $\gamma$-treated FBs (F). The $x$ axes of $\mathbf{E}$ and $\mathbf{F}$ are in log scale, since inclusion of the $\log$ (ratio) instead of the ratio led to a better model fit for FB outcomes. $P$ values refer to differences in outcome between both patient groups at stimulator/T cell ratios of 9:1 for EBV-LCLs (D) and 1:1 for FBs (E and $\mathbf{F}$ ).

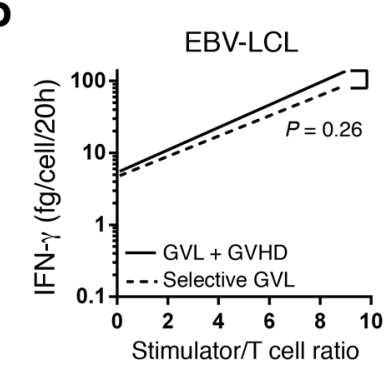

$\mathbf{E}$

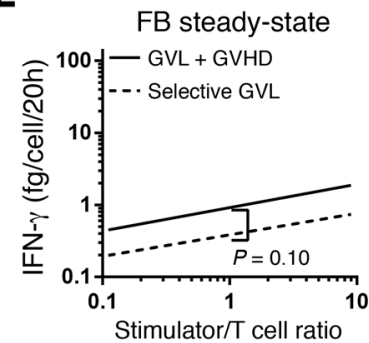

F

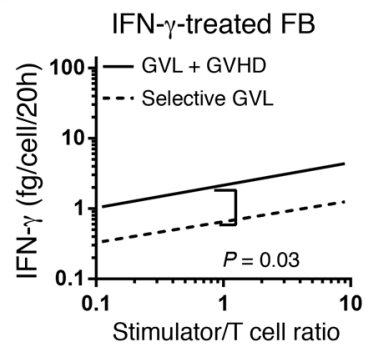

Expression of MiHA-encoding genes. To determine the potential role of alloreactive $\mathrm{T}$ cells in GVL reactivity and GVHD, we first interrogated the European Molecular Biology Laboratory - European Bioinformatics Institute (EMBL-EBI) Expression Atlas for global expression levels of MiHA-encoding genes (www.ebi.ac.uk/gxa). We classified genes on the basis of selective expression in hematopoietic tissues (bone marrow, lymph node, and spleen) as compared with tissue-independent expression (Supplemental Table 5). Expression was restricted to hematopoietic tissues for HMHA1 and $A R H G D I B$ and was more frequent in hematopoietic tissues for CCL4, NDC80, and APOBEC3B. All other genes were similarly expressed in hematopoietic and nonhematopoietic tissues and thus classified as broadly expressed genes. Next, to investigate whether the mRNA expression profiles of the identified MiHAencoding genes could explain the FB recognition patterns shown in 


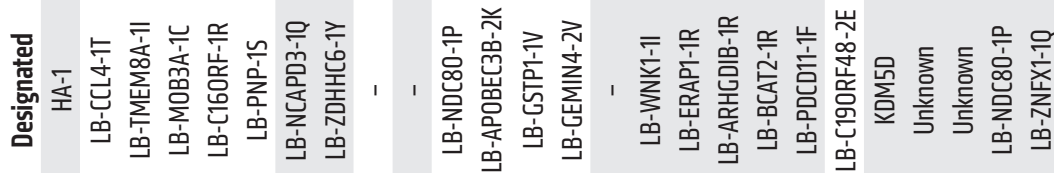

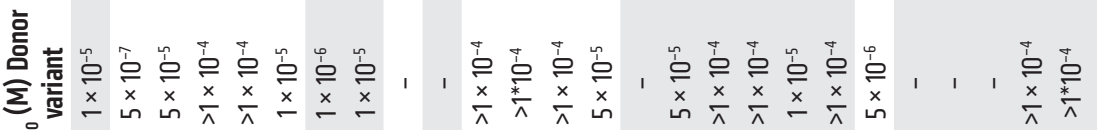
总

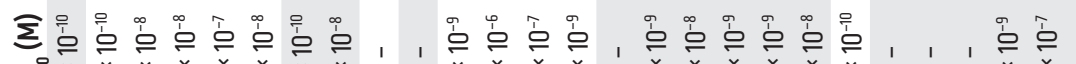

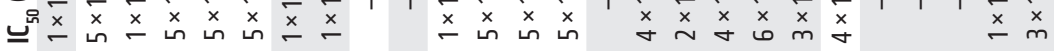

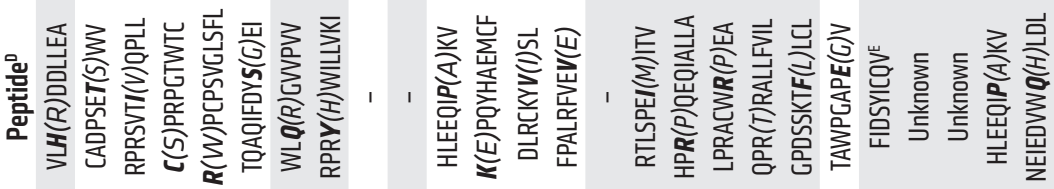

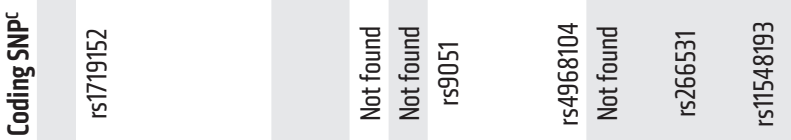

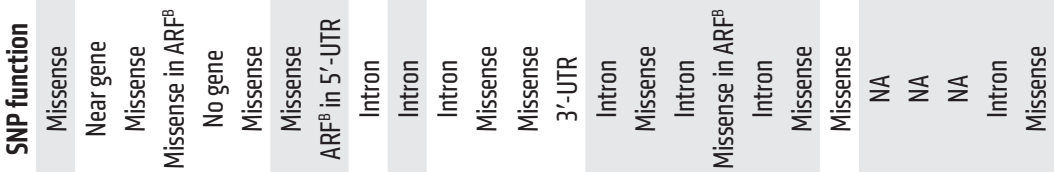

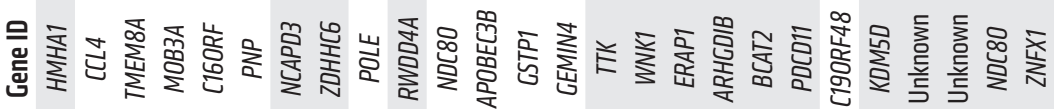
苟

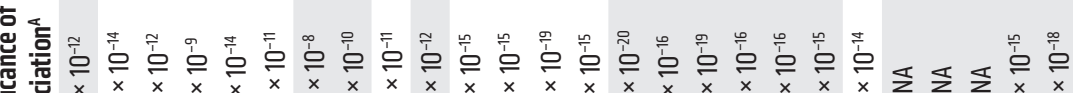

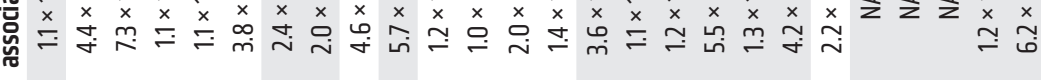

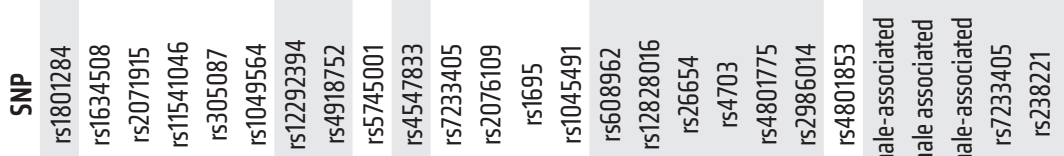

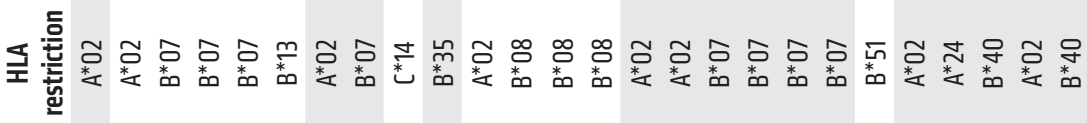

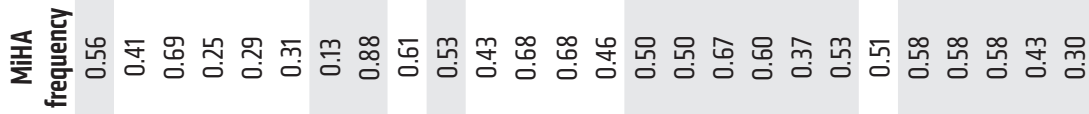


Figure 4, we quantified MiHA gene expression in third-party EBVLCLs and FBs by microarray techniques using Illumina HumanHT-12 v3 Expression BeadChips (30). Probe fluorescences of 2 of the 22 autosomal MiHA-encoding genes (CCL4 and PDCD11) and the male-specific gene (KDM5D) did not exceed background levels. Moreover, no probe was included for the LB-C16ORF-1Rencoding transcript. For $19 \mathrm{MiHAs}$, we investigated and compared gene expression (Figure 5A, left panel) with $\mathrm{T}$ cell recognition (Figure 5A, right panel) in steady-state FBs, IFN- $\gamma$-treated FBs, and EBV-LCLs. According to T cell recognition patterns of FBs, 3 different types of MiHAs could be distinguished. Type 1 MiHAs were not recognized on FBs. Type 2 MiHAs were recognized on FBs, but only after pretreatment with IFN- $\gamma$. Type 3 MiHAs were recognized on both steady-state and IFN- $\gamma$-treated FBs. Of the 19 MiHAs, 6 antigens were classified as type 1 . These antigens included 3 MiHAs targeted in patients with GVHD and 3 MiHAs targeted in patients without GVHD. For 5 of these antigens, gene expression in both steady-state and IFN- $\gamma$-treated FBs was lower than in EBVLCLs. In addition to type 1 antigens, 8 MiHAs were identified as type 2, including 4 MiHAs targeted in patients with GVHD and 4 MiHAs targeted in patients without GVHD. For all type 2 antigens, we observed no difference in gene expression between steadystate and IFN- $\gamma$-treated FBs. Furthermore, the majority of type 2 antigens did not differ in gene expression between FBs and EBVLCLs. Finally, 5 MiHAs were classified as type 3 antigens. Four of these MiHAs were targeted in patients with GVHD, and only one MiHA was targeted in a patient without GVHD. As with type 2 antigens, the majority of type 3 MiHAs did not differ in gene expression between FBs and EBV-LCLs. Since gene expression for type 2 MiHAs was comparable in steady-state and IFN- $\gamma$-treated FBs and can therefore not explain enhanced $\mathrm{T}$ cell recognition upon pretreatment with IFN- $\gamma$, we postulated that accessory molecules may be relevant and contribute to $\mathrm{T}$ cell recognition of FBs. We analyzed the expression levels of genes involved in peptide generation (PSMB8 and PSMB9), intracellular translocation (TAP1 and TAP2), and presentation ( $H L A-A, H L A-B$, and $H L A-C$ ) and observed strong upregulation of gene expression levels in IFN- $\gamma$-treated versus steady-state FBs (Figure 5B). In conclusion, our data indicate that expression of the MiHA-encoding gene is required, but not always sufficient, for $\mathrm{T}$ cell recognition of FBs and that accessory molecules may also be relevant. Furthermore, we found that there was no strict distinction in the type of MiHAs that are targeted in GVL and GVHD, but that T cell reactivity was skewed toward broadly expressed MiHAs in patients with GVHD.

\section{Discussion}

In this study, we analyzed alloreactive $\mathrm{T}$ cell responses in 11 patients who responded to DLI after T cell-depleted alloSCT and compared CD8 T cell response characteristics between patients with selective GVL reactivity and those who developed GVL reactivity in the presence of GVHD. In vivo-activated CD8 T cells were isolated, clonally expanded, and analyzed for reactivity against hematopoietic and nonhematopoietic cells representing targets for GVL and GVHD, respectively. We measured lower frequencies of MiHA-specific T cells in patients with selective GVL reactivity. Moreover, we found that TCR- $\beta$ repertoires of identified alloreactive T cells in patients with selective GVL reactivity were less diverse. Furthermore, MiHA-specific T cell clones from patients with selective GVL reactivity showed lower reactivity against FBs than did $\mathrm{T}$ cell clones from patients with GVHD, whereas all T cell clones responded equally strongly to EBV-LCLs. We identified 22 autosomal SNPs that were associated with $\mathrm{T}$ cell recognition of MiHAs and validated 19 MiHAs, including 6 known and 13 novel MiHAs. For individual MiHAs, we analyzed gene expression and $\mathrm{T}$ cell recognition using EBV-LCLs and FBs as target cells and demonstrated that MiHAs encoded by broadly expressed genes are relatively frequently targeted in patients with GVHD. However, differences in expression of the type of MiHA-encoding genes do not discriminate between patients showing GVL reactivity with or without GVHD. Our data demonstrate that both the magnitude and diversity of the alloreactive $\mathrm{T}$ cell response in patients with GVHD are higher than in those without GVHD. In patients without GVHD, the alloreactive $\mathrm{T}$ cell response was sufficiently strong to mediate GVL reactivity, but apparently below the threshold for GVHD due to skewing toward T cells that efficiently target hematopoietic cells but not nonhematopoietic cells.

Following DLI, the occurrence of clinical acute GVHD is a sign of the development of an alloimmune response that enables accurate sampling. In patients with selective GVL reactivity without GVHD, timing of the alloreactive immune response is more difficult. However, testing of multiple post-DLI samples identified alloreactive $\mathrm{T}$ cell clones in 5 of 6 patients without GVHD. It is conceivable that in 1 patient, the immune response was missed because of a lack of sample(s) at relevant time points or the occurrence of a low response magnitude. We show that the alloreactive $\mathrm{CD} 8 \mathrm{~T}$ cell repertoire resides in the HLA-DR ${ }^{+} \mathrm{T}$ cell population, indicating that an active immune response is induced after DLI. Detection of alloreactive $\mathrm{T}$ cell clones was based on selective recognition of patient- but not donor-derived hematopoietic test cells. During GVHD, responding T cells may, however, also target nonhematopoietic MiHAs. Testing FB recognition by all growing $\mathrm{T}$ cell clones from 3 patients with GVHD did not identify alloreactive $\mathrm{T}$ cell clones that failed to recognize hematopoietic cells. These results indicate that EBV-LCLs present a repertoire of MiHAs targeted in GVL and GVHD that are either specific for hematopoietic cells or more broadly expressed on hematopoietic as well as nonhematopoietic cells.

Our analyses showed a higher magnitude and diversity of CD8 alloreactivity in patients with GVHD. This could not be explained by a difference in capacity to elicit immune responses after alloSCT, since patients with selective GVL reactivity and patients with GVHD were equally able to elicit $T$ cell responses against EBV. High frequencies of EBV-LCL-reactive T cells are concordant with the observation that viral reactivation is frequent, especially in patients receiving allografts under T cell-depleting conditions (31). Although the small sample size of our cohorts limited a reliable comparison, it is noteworthy that all patients with GVHD received DLI within the first year after alloSCT as compared with only 2 of 6 patients without GVHD. It was shown that the probability to survive without GVHD was highest if DLI was given 1 year or more after alloSCT $(32,33)$. Early after alloSCT, higher levels of residual patient APCs may elicit higher response magnitudes. APCs may also persist longer as a result of the nonmyeloablative pretransplant conditioning that was given to 3 of 5 patients with GVHD 
A

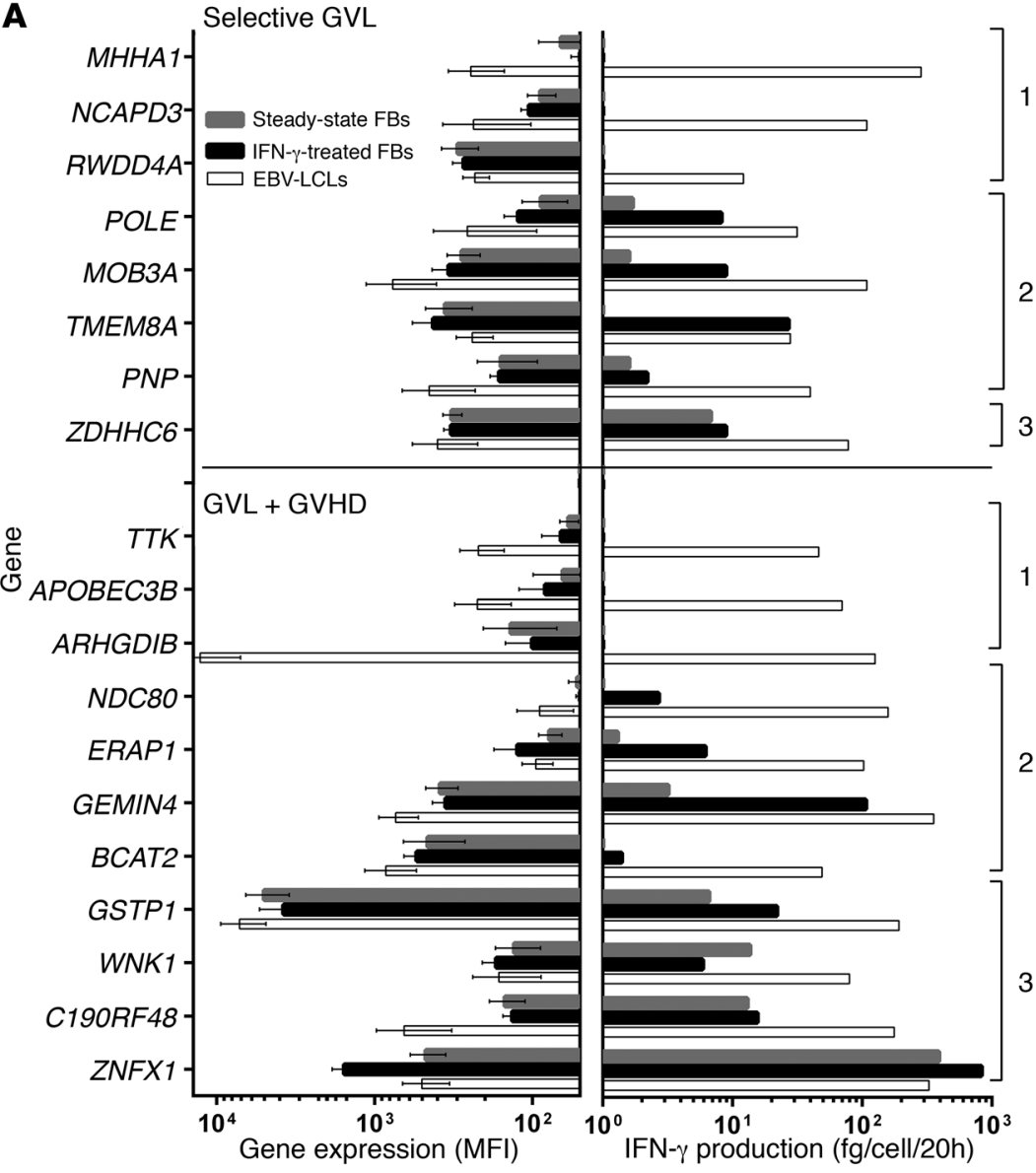

B

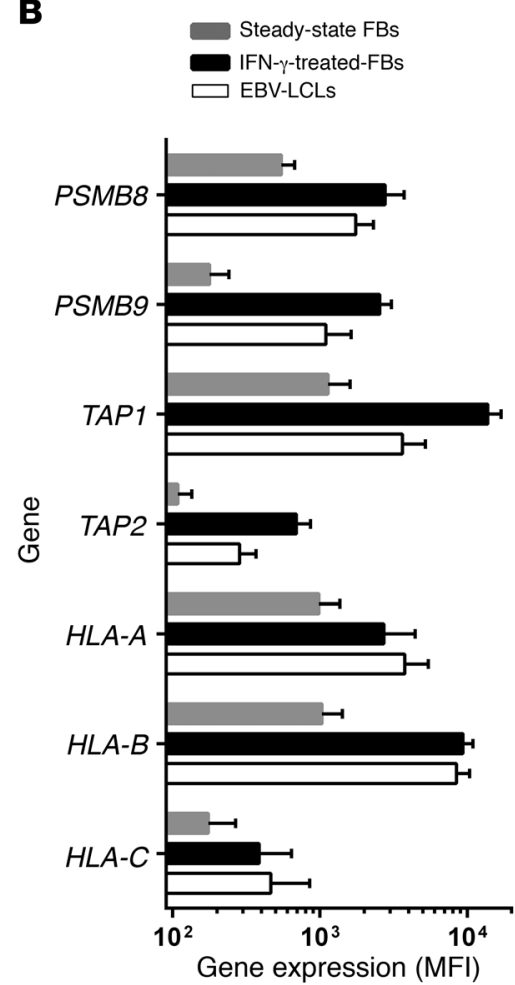

Figure 5. Gene expression for MiHA and accessory molecules Gene expression for MiHA (A) and accessory molecules (B) were determined in 6 different third-party EBV-LCLs (white bars) and 4 different FBs (gray and black bars) using Illumina Human HT-12 v3 BeadChips. FBs were analyzed in steady state (gray bars) and after treatment with 200 IU/ml IFN- $\gamma$ for 4 days (black bars). (A) Gene expression is depicted for each gene as the MFI \pm SD (left panel). T cell recognition of patient EBV-LCLs and FBs (steady-state and IFN- $\gamma$-treated) was measured by IFN- $\gamma$ ELISA after incubation at stimulator/T cell ratios of 9:1 (right panel). Specificities were stratified by the GVHD status of the patient from whom the T cell clones were isolated (top panel shows patients with selective GVL reactivity; bottom panel shows patients with GVHD). MiHA specificities with comparable recognition patterns were grouped as follows: type 1, no FB recognition; type 2, recognition of IFN- $\gamma$-treated FBs only; type 3, recognition of both steady-state and IFN- $\gamma$-treated FBs. (B) Expression of genes involved in antigen processing and presentation was analyzed, and MFI values \pm SD are depicted for the immunoproteasome subunits $P S M B 8$ and $P S M B 9$, the peptide transporters TAP1 and TAP2, and the peptide-presenting HLA-A,HLA-B, and HLA-C molecules.

as compared with 1 of 6 patients without GVHD. During immune recovery, patients are susceptible to viral infections leading to the release of inflammatory cytokines, thereby amplifying alloresponses after DLI. In addition to inflammation, disturbance of the composition of intestinal microbiota caused by pretransplant conditioning is associated with GVHD (34). Whereas genetic donorto-patient disparities determine the maximal repertoire of MiHAs that can be targeted, the presence of residual patient APCs and/or inflammatory conditions is likely to contribute to the magnitude of the alloreactive response.

In addition to higher response magnitudes, we observed stronger $\mathrm{FB}$ recognition by $\mathrm{T}$ cell clones from patients with GVHD. This was not caused by different response capacities of the T cells, since the strength of EBV-LCL recognition was comparable. MiHA recognition of EBV-LCLs and FBs indicates broad MiHA expression, whereas MiHAs that are selectively recognized on EBV-LCLs but not on FBs are more likely to be hematopoiesis specific. FB recognition after activation with IFN- $\gamma$ may be caused by a direct increase of MiHA gene expression. It may, however, also be the indirect result of more efficient processing of the antigenic peptide, stronger adhesion and costimulation, and higher HLA expression levels. Following the initiation of hematopoiesisdirected alloreactivity, the chance that $\mathrm{T}$ cells target nonhematopoietic tissues may depend on the response magnitude, since high numbers of alloreactive T cells may contribute to the inflammatory environment that increases antigen presentation on nonhematopoietic tissues, resulting in GVHD.

For one-third of the different MiHA specificities, we could identify associating SNPs and genes. Failure to characterize remaining MiHAs can be explained by high or low MiHA population frequencies, or by an absence of the MiHA-encoding SNP in the data set we used. Our WGAs panel of 80 EBV-LCLs allowed the identification of MiHA-encoding SNPs with a frequency ranging from 0.13 to 0.88 . The lack of association for 24 MiHAs can be explained by frequencies outside this range. Furthermore, our panel was genotyped for 1.1 million SNPs, which may not represent 
all SNPs that may be present. The lack of association can thus be explained by an absence of associating SNPs in our data set. MiHA identification is probably more efficient when EBV-LCLs are used that have been SNP genotyped more extensively, for example, by whole-genome sequencing. Recently, it has been demonstrated that a proportion of the HLA ligandome is encoded by "noncoding" genomic regions that are not known to contain functional genes (35). Here, we confirm that these genomic regions indeed encode relevant $\mathrm{T}$ cell epitopes, as illustrated by the characterization of LB-C16ORF-1R as a novel MiHA that is targeted by CD8 $\mathrm{T}$ cells in the setting of alloSCT and DLI. In addition to a range of novel MiHAs, we isolated T cells for a known MiHA (HA-1) and $\mathrm{T}$ cells for the novel MiHA LB-NDC80-1P that was targeted in 2 different patients. Furthermore, the genes GEMIN4, APOBEC3B, and C19ORF48 were found to encode MiHAs restricted to HLA molecules different from those previously reported $(24,36)$. Altogether, these findings suggest that, despite countless missense SNP disparities between donor and patient, a certain degree of immunodominance occurs, resulting in targeting of a limited repertoire of immunogenic polymorphic peptides. Ongoing MiHA discovery will give rise to a panel of MiHAs that are clinically relevant for both GVL reactivity and GVHD.

Despite the fact that FBs do not represent the full repertoire of nonhematopoietic cells that can be targeted in GVHD, T cell recognition and gene expression for individual MiHAs were investigated and compared in FBs from skin biopsies as the only nonhematopoietic cell type available for all selected patients. Differential $\mathrm{T}$ cell recognition patterns against $\mathrm{FBs}$ enabled clustering of 3 types of MiHAs. Type 1 MiHAs were not recognized on FBs; type 2 MiHA recognition on FBs depended on pretreatment with IFN- $\gamma$; whereas type 3 MiHAs were also recognized on nontreated FBs. For the majority of type 1 MiHAs, the absence of $\mathrm{FB}$ recognition can be explained by no or low gene expression. Strong FB recognition correlated with comparable gene expression in FBs and EBV-LCLs for the majority of type 3 MiHAs. For type 2 MiHAs, however, gene expression patterns were more diverse. Probably, surface expression of type 2 MiHAs on FBs is insufficient for T cell recognition, but inflammatory conditions may increase $\mathrm{T}$ cell recognition by enhancing antigen processing and presentation and by upregulation of costimulatory and adhesion molecules. We identified T cells specific for all 3 MiHA types, irrespective of GVHD development, and propose that during initiation of the immune response after DLI, professional APCs present all 3 MiHA types. Subsequent skewing toward more broadly expressed MiHAs may occur under inflammatory conditions, resulting in GVHD. This implies that GVHD prevention after DLI should focus on both specificity of the response and monitoring and manipulation of in vivo circumstances.

In conclusion, our data show that the magnitude and diversity of the alloreactive CD8 T cell response in patients with selective GVL reactivity are lower than in patients with GVHD, but that there is no strict separation in the type of MiHAs targeted by $\mathrm{T}$ cells in either patient group. However, the alloimmune response in patients with GVHD is skewed toward T cells with stronger FB recognition. Our data suggest that the outcome of alloSCT can be improved in favor of selective GVL reactivity, with a reduced risk of GVHD, either by $\mathrm{T}$ cell infusion for hematopoiesis-restricted MiHAs or T cell depletion for broadly expressed MiHAs.

\section{Methods}

Isolation and expansion of CD8 T cell clones. Peripheral blood mononuclear cell (PBMC) samples were thawed and washed, and CD4 T cells and monocytes were depleted using magnetic CD4 and CD14 microbeads, respectively (Miltenyi Biotec). CD8 T cell-enriched samples were stained using FITC-conjugated CD8 (BD Biosciences) and phycoerythrin-conjugated (PE-conjugated) anti-HLA-DR (BD). Single cells were sorted using a BD FACSAria device with BD FACSDiva software and collected in 96-well round-bottomed TC plates (Corning) prefilled with $100 \mu \mathrm{l}$ cell culture medium (TCM) consisting of Iscove's modified Dulbecco's medium (IMDM) (Lonza) with $5 \%$ pooled human serum (Sanquin), 5\% FBS (Lonza), $120 \mathrm{IU} / \mathrm{ml} \mathrm{IL-2} \mathrm{(Chiron),} 2 \mathrm{ng} / \mathrm{ml}$ IL-7, and $2 \mathrm{ng} / \mathrm{ml} \mathrm{IL-15} \mathrm{(Miltenyi} \mathrm{Biotec).} \mathrm{T} \mathrm{cells} \mathrm{were} \mathrm{stimulated} \mathrm{with}$ $0.8 \mu \mathrm{g} / \mathrm{ml}$ phytohemagglutinin (PHA) (Murex Biotec Ltd.) and $5 \times 10^{4}$ irradiated (50 Gy) allogeneic PBMCs. Growing T cell clones were transferred to 24-well TC plates, and remaining negative wells were restimulated under identical conditions. Alternatively, CD8 T cell clones were expanded after bulk sorting of HLA-DR ${ }^{+}$CD8 T cells, followed by manual limiting dilution in 384-well TC plates prefilled with $30 \mu \mathrm{l}$ TCM with $0.8 \mu \mathrm{g} / \mathrm{ml}$ PHA and $2.5 \times 10^{4}$ irradiated allogeneic PBMCs per well. On day 7, T cells were restimulated with $0.8 \mu \mathrm{g} / \mathrm{ml}$ PHA and $5 \times 10^{4}$ irradiated allogeneic PBMCs in $50 \mu \mathrm{l} \mathrm{TCM}$. From day 10 onward, growing $\mathrm{T}$ cell clones were collected in flat-bottomed 96-well TC plates. Expansion of selected $\mathrm{T}$ cell clones by restimulation was repeated every 14 days in TCM at $2 \times 10^{5} \mathrm{~T}$ cells per ml with $0.8 \mu \mathrm{g} / \mathrm{ml} \mathrm{PHA}$ and $1 \times 10^{6}$ allogeneic feeder cells per ml. TCM was added twice weekly.

Generation and culture of test cells. EBV-LCLs were generated from PBMCs from patients, donors, and third-party individuals and cultured in IMDM with 10\% FBS (Lonza) (37). monoDCs were generated from PBMCs after CD14 enrichment using microbeads (Miltenyi Biotec) by culturing for 2 days in IMDM with 10\% FBS, $100 \mathrm{ng} / \mathrm{ml} \mathrm{GM-CSF}$ (Novartis), and $500 \mathrm{IU} / \mathrm{ml} \mathrm{IL-4} \mathrm{(Schering-Plough),} \mathrm{followed} \mathrm{by} \mathrm{mat-}$ uration for 2 days with $10 \mathrm{ng} / \mathrm{ml} \mathrm{TNF- \alpha} \mathrm{(R \& D} \mathrm{Systems),} 10 \mathrm{ng} / \mathrm{ml}$ IL-1 $\beta$ (Immunex), $10 \mathrm{ng} / \mathrm{ml}$ IL-6 (Cellgenix), $1 \mu \mathrm{g} / \mathrm{ml}$ prostaglandin E2 (PGE2) (Sigma-Aldrich), and $500 \mathrm{IU} / \mathrm{ml} \mathrm{IFN- \gamma}$ (Boehringer Ingelheim). CD4OL B cells were generated from PBMCs after CD19 enrichment using microbeads (Miltenyi Biotec) and stimulated with irradiated (70 Gy) murine fibroblasts expressing CD4OL in IMDM with 10\% FBS and $100 \mathrm{IU} / \mathrm{ml} \mathrm{IL-4} \mathrm{(Schering-Plough).} \mathrm{Expanding} \mathrm{CD4OL}$ B cell cultures were restimulated every 2 weeks (38). Fibroblast cell lines (FBs) were obtained by seeding mechanically dissociated skin biopsies in low-glucose DMEM (Lonza) with 10\% FBS. Confluent FB cultures were trypsinized, diluted, and re-seeded. We were unable to obtain a skin biopsy from patient 4716 , but instead generated a bone marrow-derived stromal cell line. For stimulation experiments, confluently grown FB cultures were maintained in culture medium alone (steady-state FBs), or were stimulated with $200 \mathrm{IU} / \mathrm{ml} \mathrm{IFN-} \gamma$ for 4 days (activated FBs). Prior to testing, FBs were harvested by trypsinization and vigorously washed 3 times to remove IFN- $\gamma$. All cell lines used were free of mycoplasma contamination.

Testing of $T$ cell reactivity. For initial screening of growing $\mathrm{T}$ cell clones, resuspended culture aliquots were taken, washed, and diluted in $0.2 \mathrm{ml} \mathrm{IMDM}$ with $5 \%$ pooled human serum (HS), 5\% FBS, and 10 $\mathrm{IU} / \mathrm{ml} \mathrm{IL}-2$. Two thousand T cells were dispensed in $20 \mu \mathrm{l}$ in 384-well TC plates. EBV-LCLs and CD4OL B cells $\left(2 \times 10^{4}\right)$, monoDCs $\left(5 \times 10^{3}\right)$, and FBs $\left(7.5 \times 10^{3}\right)$ were added in a volume of $20 \mu$ l. For HLA-blocking experiments, frequency analysis, and WGAs, cultures of T cell clones 
were washed, diluted to $2 \times 10^{3} \mathrm{~T}$ cells per $20 \mu \mathrm{l}$, and added to $7.5 \times 10^{3}$ EBV-LCLs in $20 \mu \mathrm{l}$. After overnight incubation, IFN- $\gamma$ production was measured in $10 \mu \mathrm{l}$ aliquots by ELISA according to the manufacturer's instructions, adapted to a 384-well format (Sanquin). Recognition was defined as more than 5 times the IFN- $\gamma$ production in the absence of stimulator cells. For measurement of tissue specificity, stimulator/T cell ratios ranging from 9 to 0.1 were obtained by coculturing $7.5 \times 10^{3}$, $2.5 \times 10^{3}, 8.3 \times 10^{2}$, and $2.8 \times 10^{2}$ EBV-LCLs or FBs with $8.3 \times 10^{3}$ or 2.5 $\times 10^{2} \mathrm{~T}$ cells. ELISA was performed on undiluted, 3 -fold and 10 -fold diluted supernatants, and the amount of IFN- $\gamma$ produced per single $\mathrm{T}$ cell was calculated.

Tetramer staining. HY antigen-specific tetramers were constructed by folding peptides into biotinylated HLA monomers and multimerization using streptavidin conjugated to PE as previously described (39).

TCR- $\beta$ sequencing. TCR- $\beta$ transcripts were identified using ARTISAN PCR adapted for TCR $(40,41)$. Briefly, mRNA was isolated from T cell clones or purified CD8 T cells from PBMCs using magnetic beads (Dynabead mRNA DIRECT Kit; Invitrogen, Thermo Fisher Scientific). Messenger RNA $( \pm 10 \mu \mathrm{l})$ was mixed with 4 pmole TCR- $\beta$ constant region-specific primer and 10 pmole SA.rt anchor template-switching oligonucleotide (TSO) and denaturated for 3 minutes at $72^{\circ} \mathrm{C}$ (see also "Primers used for cDNA synthesis, amplification, and sequencing of TCR- $\beta$ " in the Supplemental Experimental Procedures). After cooling, cDNA was synthesized for 90 minutes at $42^{\circ} \mathrm{C}$ with $170 \mathrm{U}$ SMARTer reverse transcriptase (Takara, Clontech) in a total volume of $20 \mu \mathrm{l} \mathrm{con-}$ taining 30 U RNase OUT (Invitrogen, Thermo Fisher Scientific), 1.7 $\mu \mathrm{M}$ DTT (Invitrogen, Thermo Fisher Scientific), 15 pmole each of highpurity RNAse-free dNTPs (Invitrogen, Thermo Fisher Scientific) and $4.0 \mu \mathrm{l}$ of $5 \times$ first-strand buffer. During cDNA synthesis, a nontemplated $3^{\prime}$ polycytosine terminus was added, which created a template for extension of the cDNA with the TSO (42). PCR $\left(1 \mathrm{~s}\right.$ at $98^{\circ} \mathrm{C}, 40$ cycles $\times\left[15 \mathrm{~s}\right.$ at $67^{\circ} \mathrm{C}, 15 \mathrm{~s}$ at $\left.72^{\circ} \mathrm{C}\right], 2 \mathrm{~min}$ at $\left.72^{\circ} \mathrm{C}\right)$ of $5 \mu \mathrm{ldNA}$ was performed using Phusion Flash (Thermo Fisher Scientific) with 10 pmole anchor-specific primer (SA.pcr) and 5 pmole each of nested primers specific for the constant regions of TCR- $\beta .1$ and TCR- $\beta .2$. Both forward and reverse PCR primers contained overhanging sequences suitable for barcoding. Amplicons were purified and underwent a second PCR $\left(1 \mathrm{~s}\right.$ at $98^{\circ} \mathrm{C}, 10$ cycles $\times\left[15 \mathrm{~s}\right.$ at $65^{\circ} \mathrm{C}, 30 \mathrm{~s}$ at $\left.72^{\circ} \mathrm{C}\right], 2 \mathrm{~min}$ at $\left.72^{\circ} \mathrm{C}\right)$ using 10 pmole of forward and reverse primers with overhanging sequences with barcodes and adapter sequences appropriate for PacBio (Pacific Biosciences) or Illumina HiSeq platforms. Barcoded amplicons were purified, quantified, and pooled into libraries for full-length sequencing on PacBio ( $\mathrm{T}$ cell clones) or paired-end sequencing of $125 \mathrm{bp}$ on an Illumina HiSeq2500 (CD8 T cells from PBMCs). Deep sequencing was performed at the Leiden Genome Technology Center. PacBio fulllength sequences of $T$ cell clones were analyzed using IMGT/V-QUEST (43). Illumina paired-end sequences of purified CD8 T cells were analyzed with the MiXCR algorithm (44). The MixCR output was evaluated for diversity by calculating Simpson's diversity index $(45,46)$. This index measures the probability that any 2 clonotypes are different and give greater importance to the more abundant clonotypes. Simpson's diversity index ranges between 1 , for perfectly even contribution of clonotypes, and 0 , for populations that consist of a single clonotype.

HLA restriction and MiHA frequency analysis. HLA restriction of MiHA-specific $\mathrm{T}$ cell clones was determined by blocking the recognition of patient EBV-LCLs that were preincubated for 30 minutes with antibodies specific for HLA class I (W6.32), HLA-BC (B1.23.2), Bw4/A²4
(MUS4H4), Bw6 (KAM3H9), A*02 (BB7.2), B¹3 (JOK3H5), or B*35 (IND2D12). In addition, EBV-LCLs were transduced with potential HLA restriction molecules using a retroviral LZRS vector, containing the truncated nerve growth factor receptor $(\triangle \mathrm{NGFR})$ marker $(47,48)$. Retroviral supernatants were generated from HLA-A ${ }^{\star} 11$ :01, $A^{*} 24: 02$, $B^{*} 13: 02, B^{*} 35: 01, B^{*} 44: 02, B^{*} 44: 03, B^{*} 51: 01, C^{*} 05: 01, C^{*} 14: 02$, and $C^{*} 16: 01$. Nontreated 96-well plates (Greiner) were coated with Retronectin CH-296 (Clontech) and blocked with 2\% human albumin (Sanquin). Viral supernatants were diluted 3 times in IMDM with $10 \%$ FBS, and aliquots of $50 \mu \mathrm{l}$ per well were spun at 3,000 $g$ for 30 minutes. Supernatants were discarded, and $5 \times 10^{4} \mathrm{EBV}$-LCLs were transferred to each well. EBV-LCLs showed a retroviral transduction efficiency ranging from $20 \%$ to $70 \%$, as evidenced by staining with anti $\triangle$ NGFR-PE (BD).

MiHA identification. WGAs was performed as previously described (24). Briefly, a panel of 80 EBV-LCLs was genotyped for 1.1 million SNPs using microarrays. T cell recognition of the panel was measured, and recognition patterns were compared with the SNP genotype data. The level of matching between the patterns of recognition and SNP genotypes was calculated by Fisher's exact test using PLINK WGA analysis software (49). MiHA-encoding genes were amplified and Sanger sequenced from both patient- and donor-derived EBV-LCLs using cDNA that was obtained by reverse transcription of TRIzolisolated (Invitrogen, Thermo Fisher Scientific) RNA with oligo(dT) primers (Roche Diagnostics) (see also the Supplemental Experimental Procedures for the gene-specific primer sequences). Sequences were searched for donor-to-patient disparities using alignment software (Geneious). Protein sequences spanning SNP-encoded amino acid polymorphisms were analyzed by NetCTLpan to identify peptides with predicted HLA binding (28). Candidate peptides were synthesized, dissolved in DMSO, diluted in IMDM, and incubated with $2 \times 10^{4}$ donor EBV-LCLs in $20 \mu \mathrm{l}$ in 384-well TC plates for 2 hours at $37^{\circ} \mathrm{C}$. Thereafter, $2 \times 10^{3} \mathrm{~T}$ cells were added to each well in $20 \mu \mathrm{l}$, and after overnight incubation, supernatants were tested by ELISA for IFN- $\gamma$ production.

Gene expression profiles. Total RNA was isolated from EBV-LCLs and FBs using a RNAqueous Total RNA Isolation Kit and amplified with a TotalPrep RNA Amplification Kit (both from Ambion, Thermo Fisher Scientific). After preparation using a whole-genome gene expression direct hybridization assay (Illumina), samples were dispensed onto Human HT-12 v3 Expression BeadChips (Illumina) and hybridized for 17 hours at $58^{\circ} \mathrm{C}$. Mean fluorescence intensities (MFIs) were quantified using an Illumina BeadArray 500GX device. Raw data were analyzed after quantile normalization in R 2.15 (50).

Statistics. Fisher's exact test was applied to detect SNPs that associated with recognition patterns of EBV-LCL panels (see "Antigen specificity" in Table 2). The Wilcoxon matched-pairs, signed-rank test was applied to calculate the significance of difference of HLA-DR expression in paired pre- and post-DLI samples (Figure 2). A Mann-Whitney $U$ test was applied to calculate the significance of difference in unpaired magnitudes of alloreactivity (Figure 3A) and various types of response diversities between patients with selective GVL reactivity and those with GVHD (Table 1). To analyze experiments determining recognition strength and tissue specificity, mixed-models statistical analysis was applied to calculate the differences of recognition of EBVLCLs (Figure 4D), steady-state FBs (Figure 4E), and IFN- $\gamma$-treated FBs (Figure 4F) between patients with GVHD and those without GVHD and the dependence of these differences on the stimulator/T cell ratio, taking into account clustering of patients and $\mathrm{T}$ cell clones. 
Recognition of EBV-LCLs was evaluated in a separate model, while recognition of steady-state FBs and IFN- $\gamma$-treated FBs was assessed in a combined model. Linear mixed-effects models were extensions of standard linear regression models that included random effects to model correlation structures between dependent measurements. Parameters describing both fixed and random effects were estimated using a maximum likelihood approach. The estimated parameters can be used to calculate model-based predictions of outcome values for different values of the predictor variables. For a detailed description of this statistical approach including formulas and calculations, refer to the "Mixed models statistical analysis" in the Supplemental Experimental Procedures. For all statistical analyses, a $P$ value of less than 0.05 was considered significant.

Study approval. PBMCs and skin biopsies were collected from patients, donors, and third-party individuals after approval by the IRB of the Leiden University Medical Center, according to the Declaration of Helsinki. Prior written informed consent was obtained from all patients, donors, and third-party individuals to investigate materials and to publish data and case details.

\section{Author contributions}

JF conceived and designed the experiments. CvB, SvL, LdW, WH, CR, and $\mathrm{MN}$ performed the experiments. $\mathrm{ME}, \mathrm{PvB}, \mathrm{PvdB}$, and $\mathrm{SH}$ analyzed patient data. CvB, LdW, IJ, MH, MN, HV, MG, and JF analyzed experimental data. LdW, AM, and FC contributed reagents, materials, and analysis tools. $\mathrm{CvB}, \mathrm{MG}$, and JF wrote the manuscript.

\section{Acknowledgments}

The authors would like to thank Menno van der Hoorn and Guido de Roo for excellent cell sorting; Edith van der Meijden for expert technical assistance with WGAs; Marvyn Koning, Sander van der Zeeuw, Szymon Kiełbasa, and Henk Buermans for essential support with TCR- $\beta$ deep sequencing; and Michel Kester and Dirk van der Steen for the production of stable tetramers.

Address correspondence to: Cornelis A. M. van Bergen, Leiden University Medical Center, Department of Hematology, Albinusdreef 2, 2333 ZA Leiden, The Netherlands. Phone: 31.71.5264966; E-mail: c.a.m.van_bergen@lumc.nl.
1. Copelan EA. Hematopoietic stem-cell transplantation. N Engl J Med. 2006;354(17):1813-1826.

2. Horowitz MM, et al. Graft-versus-leukemia reactions after bone marrow transplantation. Blood. 1990;75(3):555-562.

3. Miller JS, et al. NCI First International Workshop on The Biology, Prevention, and Treatment of Relapse After Allogeneic Hematopoietic Stem Cell Transplantation: Report from the Committee on the Biology Underlying Recurrence of Malignant Disease following Allogeneic HSCT: Graft-versus-Tumor/Leukemia Reaction. Biol Blood Marrow Transplant. 2010;16(5):565-586.

4. Ferrara JL, Levine JE, Reddy P, Holler E. Graft-versus-host disease. Lancet. 2009;373(9674):1550-1561.

5. Kolb HJ. Graft-versus-leukemia effects of transplantation and donor lymphocytes. Blood. 2008;112(12):4371-4383.

6. Barge RM, Starrenburg CW, Falkenburg JH, Fibbe WE, Marijt EW, Willemze R. Long-term follow-up of myeloablative allogeneic stem cell transplantation using Campath "in the bag" as T-cell depletion: the Leiden experience. Bone Marrow Transplant. 2006;37(12):1129-1134.

7. Deol A, Lum LG. Role of donor lymphocyte infusions in relapsed hematological malignancies after stem cell transplantation revisited. Cancer Treat Rev. 2010;36(7):528-538.

8. Eefting M, et al. Intentional donor lymphocyteinduced limited acute graft-versus-host disease is essential for long-term survival of relapsed acute myeloid leukemia after allogeneic stem cell transplantation. Haematologica. 2014;99(4):751-758.

9. Eefting M, et al. Myeloablative T cell-depleted alloSCT with early sequential prophylactic donor lymphocyte infusion is an efficient and safe post-remission treatment for adult ALL. Bone Marrow Transplant. 2014;49(2):287-291.

10. Bloor AJ, et al. High response rate to donor lymphocyte infusion after allogeneic stem cell transplantation for indolent non-Hodgkin lymphoma. Biol Blood Marrow Transplant. 2008;14(1):50-58.

11. Thomson KJ, et al. T-cell-depleted reduced-inten- sity transplantation followed by donor leukocyte infusions to promote graft-versus-lymphoma activity results in excellent long-term survival in patients with multiply relapsed follicular lymphoma. J Clin Oncol. 2010;28(23):3695-3700.

12. Eefting M, et al. Multi-state analysis illustrates treatment success after stem cell transplantation for acute myeloid leukemia followed by donor lymphocyte infusion. Haematologica. 2016;101(4):506-514.

13. Shlomchik WD. Graft-versus-host disease. Nat Rev Immunol. 2007;7(5):340-352.

14. Kolb HJ, et al. Donor leukocyte transfusions for treatment of recurrent chronic myelogenous leukemia in marrow transplant patients. Blood. 1990;76(12):2462-2465.

15. Barge RM, et al. Minimal GVHD following in-vitro T cell-depleted allogeneic stem cell transplantation with reduced-intensity conditioning allowing subsequent infusions of donor lymphocytes in patients with hematological malignancies and solid tumors. Exp Hematol. 2003;31(10):865-872.

16. Falkenburg JH, Warren EH. Graft versus leukemia reactivity after allogeneic stem cell transplantation. Biol Blood Marrow Transplant. 2011;17(1 Suppl):S33-S38.

17. Griffioen M, van Bergen CA, Falkenburg JH. Autosomal Minor Histocompatibility Antigens: How Genetic Variants Create Diversity in Immune Targets. Front Immunol. 2016;7:100.

18. Feng X, Hui KM, Younes HM, Brickner AG. Targeting minor histocompatibility antigens in graft versus tumor or graft versus leukemia responses. Trends Immunol. 2008;29(12):624-632.

19. Alyea EP, et al. CD8+ cell depletion of donor lymphocyte infusions using cd8 monoclonal antibody-coated high-density microparticles (CD8-HDM) after allogeneic hematopoietic stem cell transplantation: a pilot study. Bone Marrow Transplant. 2004;34(2):123-128.

20. Meyer RG, et al. Prophylactic transfer of CD8depleted donor lymphocytes after T-celldepleted reduced-intensity transplantation.
Blood. 2007;109(1):374-382.

21. Orti G, et al. Phase I study of high-stringency CD8 depletion of donor leukocyte infusions after allogeneic hematopoietic stem cell transplantation. Transplantation. 2009;88(11):1312-1318.

22. Oostvogels R, Lokhorst HM, Mutis T. Minor histocompatibility Ags: identification strategies, clinical results and translational perspectives. Bone Marrow Transplant. 2016;51(2):163-171.

23. Griffioen $M$, et al. Identification of 4 novel HLA-B ${ }^{*}$ 40:01 restricted minor histocompatibility antigens and their potential as targets for graft-versus-leukemia reactivity. Haematologica. 2012;97(8):1196-1204.

24. Van Bergen CA, et al. High-throughput characterization of 10 new minor histocompatibility antigens by whole genome association scanning. Cancer Res. 2010;70(22):9073-9083.

25. van Bergen CA, et al. Multiple myeloma-reactive $T$ cells recognize an activation-induced minor histocompatibility antigen encoded by the ATP-dependent interferon-responsive (ADIR) gene. Blood. 2007;109(9):4089-4096.

26. Hobo W, et al. Association of disparities in known minor histocompatibility antigens with relapsefree survival and graft-versus-host disease after allogeneic stem cell transplantation. Biol Blood Marrow Transplant. 2013;19(2):274-282.

27. Stevanovic S, et al. HLA class II upregulation during viral infection leads to HLA-DP-directed graft-versus-host disease after CD4+ donor lymphocyte infusion. Blood. 2013;122(11):1963-1973.

28. Stranzl T, Larsen MV, Lundegaard C, Nielsen M. NetCTLpan: pan-specific MHC class I pathway epitope predictions. Immunogenetics. 2010;62(6):357-368.

29. den Haan JM, et al. The minor histocompatibility antigen HA-1: a diallelic gene with a single amino acid polymorphism. Science. 1998;279(5353):1054-1057.

30. Pont MJ, et al. Microarray Gene Expression Analysis to Evaluate Cell Type Specific Expression of Targets Relevant for Immunotherapy of Hematological Malignancies. PLOS ONE. 
2016;11(5):e0155165.

31. van Esser JW, et al. Epstein-Barr virus (EBV) reactivation is a frequent event after allogeneic stem cell transplantation (SCT) and quantitatively predicts EBV-lymphoproliferative disease following T-cell--depleted SCT. Blood. 2001;98(4):972-978.

32. MacDonald KP, Shlomchik WD, Reddy P. Biology of graft-versus-host responses: recent insights. Biol Blood Marrow Transplant. 2013;19 (1 Suppl):S10-S14.

33. Radujkovic A, et al. Donor Lymphocyte Infusions for Chronic Myeloid Leukemia Relapsing after Allogeneic Stem Cell Transplantation: May We Predict Graft-versus-Leukemia Without Graftversus-Host Disease? Biol Blood Marrow Transplant. 2015;21(7):1230-1236.

34. Jenq RR, et al. Intestinal Blautia Is Associated with Reduced Death from Graft-versusHost Disease. Biol Blood Marrow Transplant. 2015;21(8):1373-1383.

35. Laumont CM, et al. Global proteogenomic analysis of human MHC class I-associated peptides derived from non-canonical reading frames. Nat Commun. 2016;7:10238.

36. Tykodi SS, et al. C19orf 48 encodes a minor histocompatibility antigen recognized by CD $8+$ cytotoxic $\mathrm{T}$ cells from renal cell carcinoma patients. Clin Cancer Res. 2008;14(16):5260-5269.
37. Miller G, Shope T, Lisco H, Stitt D, Lipman M. Epstein-Barr virus: transformation, cytopathic changes, and viral antigens in squirrel monkey and marmoset leukocytes. Proc Natl Acad Sci USA. 1972;69(2):383-387.

38. Wiesner M, et al. Conditional immortalization of human $\mathrm{B}$ cells by CD40 ligation. PLOS ONE. 2008;3(1):e1464.

39. Burrows SR, Kienzle N, Winterhalter A, Bharadwaj M, Altman JD, Brooks A. Peptide-MHC class I tetrameric complexes display exquisite ligand specificity. JImmunol. 2000;165(11):6229-6234.

40. Nagler M, Wuillemin WA. Patient selfmanagement of oral anticoagulation with vitamin $\mathrm{K}$ antagonists in everyday practice: comment on Jennings, et al British Journal of Haematology, 2014, 167:600-607. Br J Haematol. 2015;169(4):600-601.

41. Koning MT, Nteleah V, Veelken H, Navarrete MA. Template-switching anchored polymerase chain reaction reliably amplifies functional lambda light chain transcripts of malignant lymphoma. Leuk Lymphoma. 2014;55(5):1212-1214.

42. Zhu YY, Machleder EM, Chenchik A, Li R, Siebert PD. Reverse transcriptase template switching: a SMART approach for full-length cDNA library construction. BioTechniques. 2001;30(4):892-897. 43. Lefranc MP, et al. IMGT, the international ImMuno-
GeneTics information system 25 years on. Nucleic Acids Res. 2015;43(Database issue):D413-D422.

44. Bolotin DA, et al. MiXCR: software for comprehensive adaptive immunity profiling. Nat Methods. 2015;12(5):380-381.

45. Venturi V, Kedzierska K, Turner SJ, Doherty PC, Davenport MP. Methods for comparing the diversity of samples of the $\mathrm{T}$ cell receptor repertoire. JImmunol Methods. 2007;321(1-2):182-195.

46. Mahajan VS, Leskov IB, Chen JZ. Homeostasis of T cell diversity. Cell Mol Immunol. 2005;2(1):1-10.

47. Heemskerk MH, Hoogeboom M, Hagedoorn R, Kester MG, Willemze R, Falkenburg JH. Reprogramming of virus-specific $\mathrm{T}$ cells into leukemia-reactive $\mathrm{T}$ cells using $\mathrm{T}$ cell receptor gene transfer. JExp Med. 2004;199(7):885-894.

48. Griffioen M, et al. Genetic engineering of virusspecific $\mathrm{T}$ cells with $\mathrm{T}$-cell receptors recognizing minor histocompatibility antigens for clinical application. Haematologica. 2008;93(10):1535-1543.

49. Purcell S, et al. PLINK: a tool set for whole-genome association and population-based linkage analyses. Am J Hum Genet. 2007;81(3):559-575.

50. Bolstad BM, Irizarry RA, Astrand M, Speed TP. A comparison of normalization methods for high density oligonucleotide array data based on variance and bias. Bioinformatics. 2003;19(2):185-193. 